Research report

\title{
Aldosterone infusion into the 4th ventricle produces sodium appetite with baroreflex attenuation independent of renal or blood pressure changes
}

\author{
S. Gasparini ${ }^{\mathrm{a}, \mathrm{b}}$, M.R. Melo a , G.M.F. Andrade-Franzée ${ }^{\mathrm{a}}$, J.C. Geerling ${ }^{\mathrm{b}}$, J.V. Menani ${ }^{\mathrm{a}}$, E. Colombari ${ }^{\mathrm{a}, *}$ \\ a Department of Physiology and Pathology, School of Dentistry, São Paulo State University, UNESP, Araraquara, SP, Brazil \\ ${ }^{\mathrm{b}}$ Departament of Neurology, University of Iowa Carver College of Medicine, Iowa City, IA, USA
}

\section{A R T I C L E I N F O}

\section{Article history:}

Received 8 February 2018

Received in revised form 5 May 2018

Accepted 16 June 2018

Available online 18 June 2018

\section{Keywords:}

Aldosterone

Sodium ingestion

Sodium excretion

Baroreflex

HDS2 neurons

\begin{abstract}
A B S T R A C T
Aldosterone infusion into the 4 th ventricle ( 4 th $\mathrm{V}$ ), upstream the nucleus of the solitary tract (NTS), produces strong $0.3 \mathrm{M} \mathrm{NaCl}$ intake. In the present study, we investigated whether aldosterone infusion into the 4th V activates HSD2 neurons, changes renal excretion, or alters blood pressure and cardiovascular reflexes. Chronic infusion of aldosterone $(100 \mathrm{ng} / \mathrm{h})$ into the 4th $\mathrm{V}$ increased daily $0.3 \mathrm{M} \mathrm{NaCl}$ intake (up to $44 \pm 10$, vs. vehicle: $5.6 \pm 3.4 \mathrm{ml} / 24 \mathrm{~h}$ ) and also c-Fos expression in HSD2 neurons in the NTS and in non-HSD2 neurons in the NTS. Natriuresis, diuresis and positive sodium balance were present in rats that ingested $0.3 \mathrm{M} \mathrm{NaCl}$, however, renal excretion was not modified by 4 th $\mathrm{V}$ aldosterone in rats that had no access to $\mathrm{NaCl}$. 4 th $\mathrm{V}$ aldosterone also reduced baroreflex sensitivity $(-2.8 \pm 0.5$, vs. vehicle: $-5.1 \pm 0.9 \mathrm{bpm} / \mathrm{mmHg}$ ) in animals that had sodium available, without changing blood pressure. The results suggest that sodium intake induced by aldosterone infused into the 4 th $\mathrm{V}$ is associated with activation of NTS neurons, among them the HSD2 neurons. Aldosterone infused into the 4th V in association with sodium intake also impairs baroreflex sensitivity, without changing arterial pressure.
\end{abstract}

(c) 2018 Elsevier B.V. All rights reserved.

\section{Introduction}

The renin-angiotensin-aldosterone system (RAAS) is an important hormonal mechanism activated in response to water and/or sodium deficiency in the body (Fitzsimons, 1998; Johnson and Thunhorst, 2007). Angiotensin II (ANG II) has numerous physiological functions, increasing blood pressure, sodium excretion, water and sodium intake, vasopressin secretion and sympathetic activity (Daniels et al., 2009; Fitzsimons, 1998; Liu et al., 2014; Xue et al., 2011). In addition to ANG II, the mineralocorticoid aldosterone plays an important role in the control of sodium in the body, acting on mineralocorticoid receptors (MR) located peripherally in the kidney and in the colon to regulate the (re)absorption of sodium and secretion of potassium, as well as centrally, inducing sodium appetite (Booth et al., 2002; Evans et al., 2016; Formenti et al., 2013; Geerling et al., 2006a; Geerling and Loewy, 2007; Sakai et al., 1996). Both aldosterone and glucocorticoids bind to MR, so selectivity for aldosterone depends on the presence of the enzyme

\footnotetext{
* Corresponding author at: Department of Physiology and Pathology, School of Dentistry, Sao Paulo State University, UNESP, Rua Humaitá, 1680, 14801-903 Araraquara, SP, Brazil.

E-mail address: eduardo.colombari@unesp.br (E. Colombari).
}

$11 \beta$ hydroxysteroid dehydrogenase type 2 (HSD2), which catalyzes the conversion of endogenous glucocorticoid, cortisol (in humans) and corticosterone (in rodents), into biologically inactive analogs (Naray-Fejes-Toth and Fejes-Toth, 1996; Odermatt et al., 1999; Odermatt et al., 2001). Therefore, the presence of the HSD2 enzyme allows only aldosterone to have access to MR. Aldosterone sensitive neurons (those containing the HSD2 enzyme and MR) are present in the nucleus of the solitary tract (NTS) at the back of the 4th $\mathrm{V}$ (Geerling et al., 2006b). The HSD2 neurons from the NTS project to important areas involved in the control of sodium intake, including the lateral parabrachial nucleus (LPBN) and the bed nucleus of the stria terminalis (Geerling and Loewy, 2006b; Geerling and Loewy, 2006c). These HSD2 neurons are activated under various conditions that stimulate sodium intake (Geerling and Loewy, 2006a; Geerling and Loewy, 2007), and activating or ablating them stimulates or reduces sodium consumption (Jarvie and Palmiter, 2017; Resch et al., 2017), suggesting that they play an important role in sensing the need for sodium and generating sodium appetite.

In addition to the neuroanatomical studies, functional studies have shown that chronic infusion of low dose of aldosterone into the 4 th ventricle ( 4 th $\mathrm{V}$ ) induces strong daily $\mathrm{NaCl}$ intake in rats, without changing food and water intake or body weight 
(Formenti et al., 2013). This effect is blocked by an MR antagonist (Formenti et al., 2013) and the knockdown of MR receptors in the NTS reduces sodium appetite induced by aldosterone infusion into the 4th $\mathrm{V}$, suggesting that aldosterone acting on hindbrain MR induces sodium intake (Koneru et al., 2014). Further, systemic inhibition of HSD2 in rats, which exposes MR in aldosterone target cells to glucocorticoids, increases sodium appetite despite also increasing sodium retention (Cooney and Fitzsimons, 1996) and the brain-specific deletion of $\mathrm{Hsd} 11 \mathrm{~b} 2$ in mice produces sodium intake, baroreflex attenuation and hypertension (Evans et al., 2016). Spironolactone, an antagonist of MR, reduced sodium intake in these $H s d 11$ b2 brain-deleted mice, suggesting important role of MR for this effect (Evans et al., 2016). Although the deletion of Hsd11b2 increases sodium intake, it is not clear if aldosterone infusion into the 4th V affects the activity of HSD2 neurons in the NTS or non-HSD2 neurons.

Besides the control of sodium in the body, aldosterone may also affect arterial pressure. The administration of aldosterone into the lateral ventricle increases arterial pressure, a response suggested to depend on increased sympathetic activity and abolished by the administration of MR antagonist (Gomez-Sanchez et al., 1990; van den Berg et al., 1989). The subcutaneous (s.c.) infusion of aldosterone also causes hypertension that was reduced by silencing NADPH oxidase isoform NOX2 and NOX4 in the hypothalamic paraventricular nucleus (PVN) (Xue et al., 2012). Moreover, MR and HSD2 in the PVN are suggested to affect sympathetic activity (Zhang et al., 2006). However, no study investigated if aldosterone acting in the hindbrain changes arterial pressure, particularly at the dose that it produces sodium appetite. Studies showing that the MR antagonist spironolactone increased baroreceptor reflex sensitivity in a renovascular hypertension model or that injection of the MR antagonist eplerenone into the NTS increased baroreflex sensitivity in salt-loaded rats suggest that endogenous aldosterone or corticosterone may be involved in the control of baroreflex function (Lincevicius et al., 2015; Masuda et al., 2010).

The deletion of Hsd11b2 in mice increases sodium intake, without changing sodium excretion, suggesting no correlation between sodium intake and sodium excretion (Evans et al., 2016). In spite of this, chronic infusion of aldosterone in the region of the subcommissural organ (SCO), near the aqueduct, induces natriuresis (Dundore et al., 1984) which opens the possibility that sodium intake induced by aldosterone infused into the 4th $\mathrm{V}$ is secondary to sodium appetite produced by an increase in sodium excretion. Thus, it seems important to investigate the renal excretion in rats treated with chronic infusion of aldosterone into the 4th $\mathrm{V}$ with or without access to hypertonic $\mathrm{NaCl}$ to ingest.

Therefore, in the present study, we investigated if sodium appetite produced by aldosterone infused into the 4 th $\mathrm{V}$ is influenced by changes in renal excretion and if it influences the activity of HSD2 neurons in the NTS. In addition, arterial pressure, cardiovascular reflexes and plasma renin activity (PRA) were also tested in rats treated with aldosterone into the 4 th $\mathrm{V}$.

\section{Results}

\subsection{Expression of c-Fos in HSD2 neurons and in other NTS neurons in animals treated with aldosterone infusion into the 4 th $\mathrm{V}$}

The infusion of aldosterone into the 4 th $\mathrm{V}$ induced c-Fos expression in HSD2 neurons of the intermediate NTS ( $3 \pm 1$, vs. vehicle: 0 \pm 0 cells/section, $\mathrm{p}<0.05)$ and rostral NTS $(7 \pm 2$, vs. vehicle: $0 \pm 0$ cells/section, $\mathrm{p}<0.05$ ) (Figs. 1A-D and 2). Although c-Fos activation in HSD2 neurons of the caudal NTS was not statistically different between the groups, double labeling was present in two animals ( $2 \pm 2$, vs. vehicle: $0 \pm 0$ cells/section, $\mathrm{p}>0.05)$. In addition, $\mathrm{c}$-Fos expression also increased in non-HSD2 neurons in the caudal NTS in animals treated with aldosterone infusion into the 4th V (aldosterone, $\mathrm{n}=5: 22 \pm 6$ vs. vehicle, $\mathrm{n}=4: 5 \pm 3$ cells/section, $\mathrm{p}$ $<0.05$ ) (Fig. 2).

In the rats used for immunohistochemistry, chronic infusion of aldosterone $(100 \mathrm{ng} / \mathrm{h})$ into the 4 th $\mathrm{V}$ during $2 \mathrm{~h}$ daily access increased daily $0.3 \mathrm{M} \mathrm{NaCl}$ intake $(10.3 \pm 3$, vs. vehicle: $2.3 \pm 1 \mathrm{~m}$ $1 / 2 \mathrm{~h})[\mathrm{F}(1,7)=71.64 ; \mathrm{p}<0.05]$, without significantly changing daily water intake $(1.7 \pm 0.7$, vs. vehicle: $0.6 \pm 0.4 \mathrm{ml} / 2 \mathrm{~h})$ [F (1, 7) $=1.41 ; p>0.05]$.

Fig. 1E shows the tract of the cannula directed to the 4 th $\mathrm{V}$. In the present study, the injections into the 4 th $\mathrm{V}$ were performed upstream of the NTS, where HSD2 neurons are located.

\subsection{Daily fluid ingestion and renal excretion in rats infused with aldosterone into 4 th $\mathrm{V}$}

Daily fluid ingestion and renal excretion were analyzed in rats with and without access to $0.3 \mathrm{M} \mathrm{NaCl}$ ad libitum.

In rats with access to $0.3 \mathrm{M} \mathrm{NaCl}$, chronic infusion of aldosterone $(100 \mathrm{ng} / \mathrm{h})$ into the 4 th $\mathrm{V}$ strongly increased daily $0.3 \mathrm{M}$ $\mathrm{NaCl}$ intake (aldosterone, $\mathrm{n}=8$ : up to $44 \pm 10$, vs. vehicle, $\mathrm{n}=7$ : $5.6 \pm 3.4 \mathrm{ml} / 24 \mathrm{~h})[\mathrm{F}(1,117)=42.42 ; \mathrm{p}<0.05]$, urinary sodium excretion (up to $8.17 \pm 2.2$, vs. vehicle: $2.2 \pm 1.6 \mathrm{mEq} / 24 \mathrm{~h}$ ) [F ( 1 , 117 ) $=12.81 ; p<0.05]$, urinary volume (up to $29.1 \pm 6.8$, vs. vehicle infusion: $6.4 \pm 1.3 \mathrm{ml} / 24 \mathrm{~h})[\mathrm{F}(1,117)=59.25$; $\mathrm{p}<0.05)$ and kaliuresis (up to $7.2 \pm 1.8 \mathrm{mEq} / 24 \mathrm{~h}$, vs. vehicle: $2.4 \pm 0.2$ to $2.7 \pm 0.4$ $\mathrm{mEq} / 24 \mathrm{~h})[\mathrm{F}(1,117)=19.98 ; \mathrm{p}<0.05]$. Aldosterone-infused rats showed a variable, slight reduction in water intake some days, but across the treatment period this was not significantly different from the control group $[F(1,117)=0.03 ; p>0.05]$ (Fig. 3A-D and Table 3 ). Aldosterone infusion also produced a positive sodium balance (up to $6.4 \pm 2.9$ on the 6 th day of infusion, vs. vehicle: $0.4 \pm 2$. $2 \mathrm{mEq} / 24 \mathrm{~h})[\mathrm{F}(1,117)=12.81 ; \mathrm{p}<0.05)]$ (Fig. 3E) . As a consequence of the increases in $0.3 \mathrm{M} \mathrm{NaCl}$ intake, the total fluid intake also increased in rats infused with aldosterone into the 4th $\mathrm{V}$ (up to $71.4 \pm 4.6 \mathrm{ml} / 24 \mathrm{~h}$, vs. vehicle infusion: $41 \pm 3.7 \mathrm{ml} / 24 \mathrm{~h}$ ) [F (1, 117 ) $=29.43 ; p<0.05]$ (Fig. 3F).

In rats that had no access to ingest $0.3 \mathrm{M} \mathrm{NaCl}$, chronic infusion of aldosterone ( $100 \mathrm{ng} / \mathrm{h}$ ) into the 4 th $\mathrm{V}$ did not modify daily water intake (aldosterone, $\mathrm{n}=8: 40 \pm 7 \mathrm{ml} / 24 \mathrm{~h}$, vs. vehicle, $\mathrm{n}=6: 39.7 \pm$ $6.4 \mathrm{ml} / 24 \mathrm{~h})[\mathrm{F}(1,108)=0.42 ; \mathrm{p}>0.05]$, urinary sodium excretion (up to $0.9 \pm 0.1 \mathrm{mEq} / 24 \mathrm{~h}$, vs. vehicle infusion: $0.7 \pm 0.1 \mathrm{mEq} / 24 \mathrm{~h}$ ) $[\mathrm{F}(1,108)=2.02 ; \mathrm{p}>0.05]$ or urinary volume (up to $11.6 \pm 2.4$, vs. vehicle infusion: $9.3 \pm 1.2 \mathrm{ml} / 24 \mathrm{~h})[\mathrm{F}(1,108)=0.33$; $\mathrm{p}<0.05$ ] (Fig. $4 \mathrm{~A}-\mathrm{C}$ ). The infusion of aldosterone into the 4 th $\mathrm{V}$ did reduce potassium excretion (up to $2.5 \pm 0.3$, vs. vehicle infusion: $4.4 \pm 0$. $8 \mathrm{mEq} / 24 \mathrm{~h})[\mathrm{F}(1,108)=15.10 ; \mathrm{p}<0.05]$ (Table 1$)$.

\subsection{Arterial pressure and heart rate in rats infused with aldosterone into the 4 th $V$}

In rats with access to water and $0.3 \mathrm{M} \mathrm{NaCl}$, chronic infusion of aldosterone did not modify mean arterial pressure recorded by telemetry in the light (aldosterone, $\mathrm{n}=13$ : $110 \pm 10$, vs. vehicle, $\mathrm{n}=7: 108 \pm 2 \mathrm{mmHg}$ ) [F $(1,270)=3.47 ; \mathrm{p}>0.05]$ or dark period $(108 \pm 7$, vs. vehicle: $103 \pm 7 \mathrm{mmHg})[\mathrm{F}(1,270)=1.56$; $\mathrm{p}>0.05]$ (Fig. $5 \mathrm{~A}$ and $\mathrm{B}$ ). HR was also not different between groups in the light (333 \pm 17 , vs. vehicle: $357 \pm 16 \mathrm{mmHg}$ ) $[\mathrm{F}(1,270)=3.47 ; \mathrm{p}$ $>0.05$ ] or dark period ( $381 \pm 8$, vs. vehicle: $390 \pm 12 \mathrm{bpm})$ [F (1, $270)=1.56 ; \mathrm{p}>0.05]$ (Table 2). The infusion of aldosterone $(100$ $\mathrm{ng} / \mathrm{h}$ ) into the 4 th $\mathrm{V}$ in the same rats strongly increased daily 0.3 $\mathrm{M} \mathrm{NaCl}$ intake (up to $43 \pm 13$, vs. vehicle: $5.1 \pm 1.6 \mathrm{ml} / 24 \mathrm{~h}$ ) [F (1, $271)=83.68 ; \mathrm{p}<0.05$ ] (Table 3 ) and decreased water intake on 


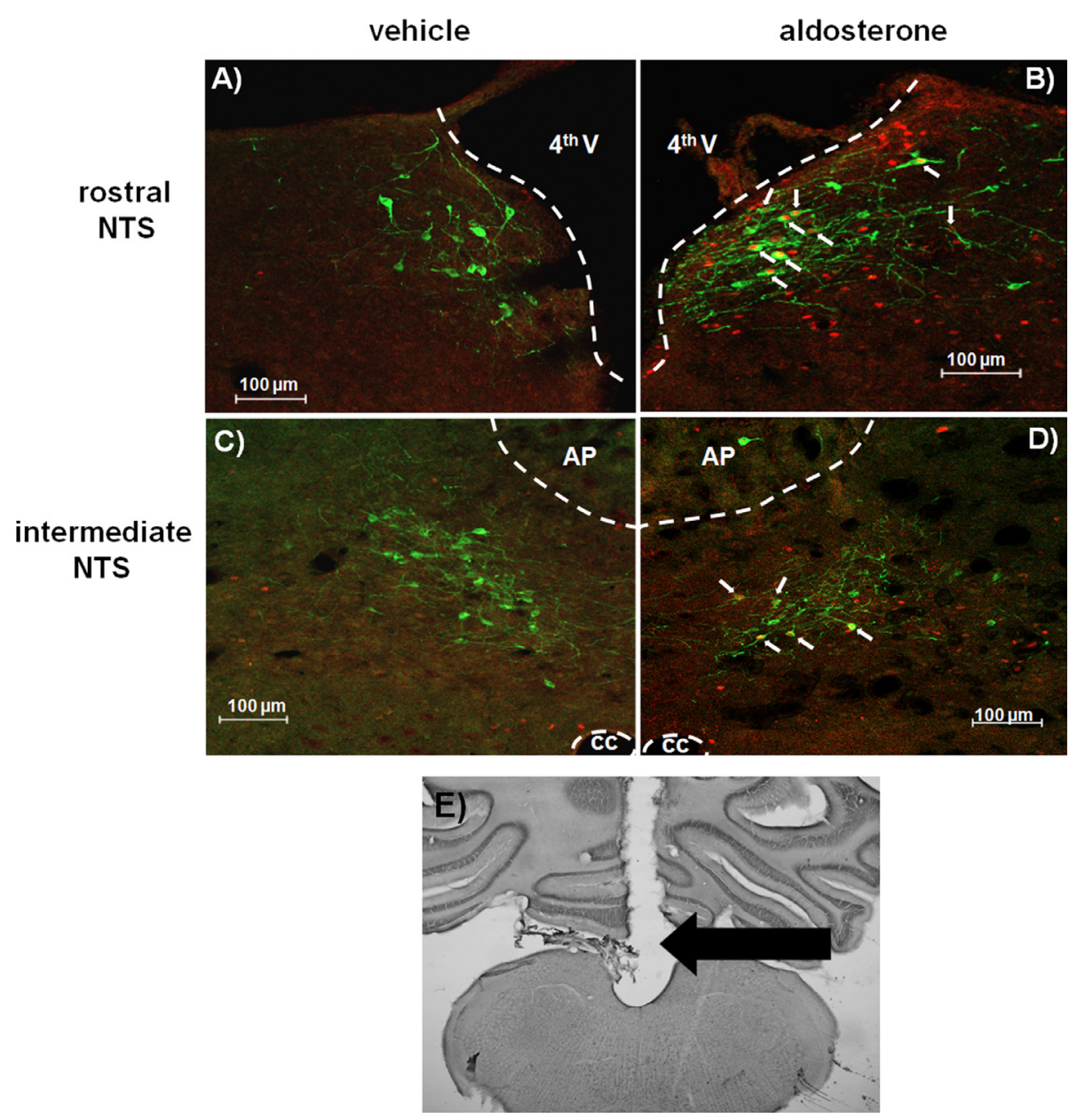

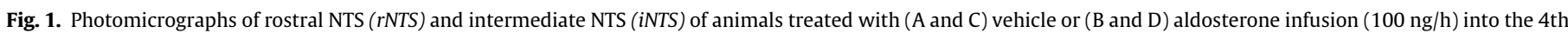

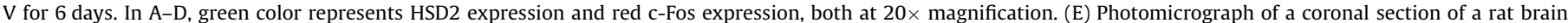
showing the injection site into the 4th $\mathrm{V}$ (arrow).

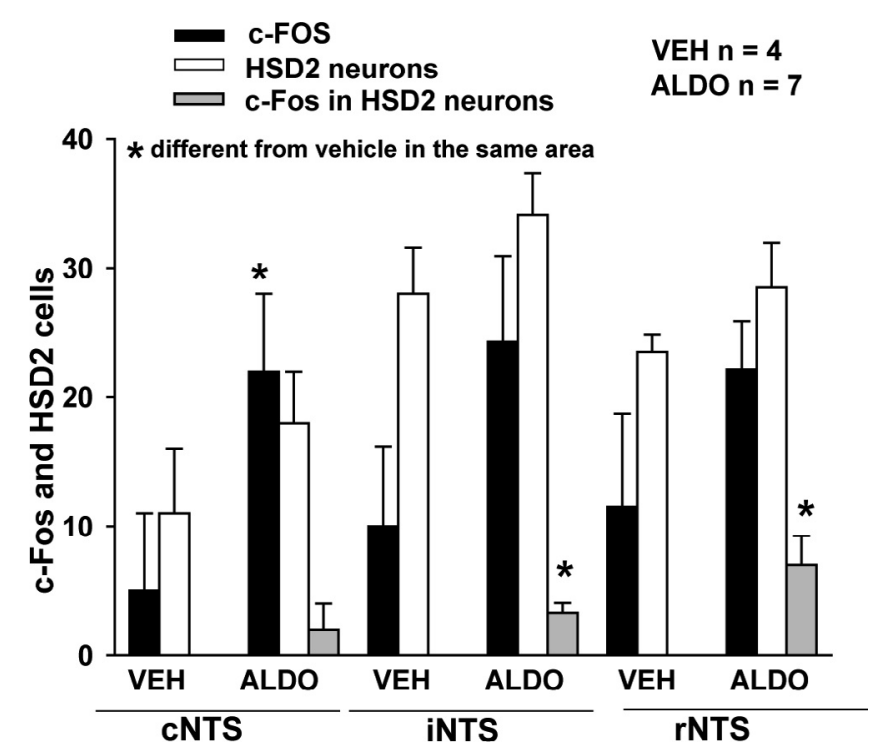

Fig. 2. Quantitative c-Fos and HSD2 expression in the caudal NTS (cNTS), intermediate NTS (iNTS) and rostral NTS (rNTS) in animals treated with vehicle (VEH) or aldosterone (ALDO) infusion $(100 \mathrm{ng} / \mathrm{h})$ into the 4 th $\mathrm{V}$ for 6 days. Data expressed as means \pm SEM. the 2 nd, 5th, 8th and 12 nd day of treatment $[\mathrm{F}(1,271)=25.14 ; \mathrm{p}<$ 0.05] (Table 3).

\subsection{Cardiovascular reflexes in rats infused with aldosterone into the} 4th $\mathrm{V}$

Cardiovascular reflexes were tested in rats with and without access to $0.3 \mathrm{M} \mathrm{NaCl}$ ad libitum.

In rats that had access to $0.3 \mathrm{M} \mathrm{NaCl}$ to ingest, on the 7th day of aldosterone infusion into the 4 th $\mathrm{V}$, baroreflex reduction in HR was blunted in response to intravenous phenylephrine (aldosterone, $\mathrm{n}$ = 5: slope: $-0.72 \pm 0.25$, vs. vehicle, $\mathrm{n}=4:-5.1 \pm 0.9 \mathrm{bpm} / \mathrm{mmHg}$, $\mathrm{R}=0$ ) (Fig. 6A), but there was no difference with nitroprusside (slope: $-1.93 \pm 0.52$, vs. vehicle: $-1.15 \pm 0.9 \mathrm{bpm} / \mathrm{mmHg}, \mathrm{R}=$ 0.246). (Fig. 6B). The bradycardic response to chemoreflex activation with intravenous potassium cyanide was also reduced $(-30$ \pm 12 , vs. vehicle: $-101 \pm 15 \mathrm{bpm})[\mathrm{F}(1,7)=9.12$; $\mathrm{p}<0.05]$, without changing the pressor response (Fig. 6C, D). However, infusion of aldosterone did not change the cardiopulmonary reflex tested with intravenous injection of the 5HT3 agonist phenylbiguanide (Fig. 6C, D) in the same group of animals. The infusion of aldosterone into the 4 th $\mathrm{V}$ in these rats again did not modify MAP $(107 \pm 4$, vs. vehicle: $99 \pm 4 \mathrm{mmHg})[\mathrm{F}(1,7)=3.19 ; \mathrm{p}>0.05]$ or HR $(395 \pm 16$, vs. vehicle: $355 \pm 20$ bpm $[F(1,7)=2.19 ; p>0.05]$. 


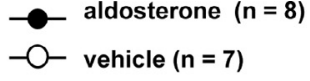

* different from vehicle
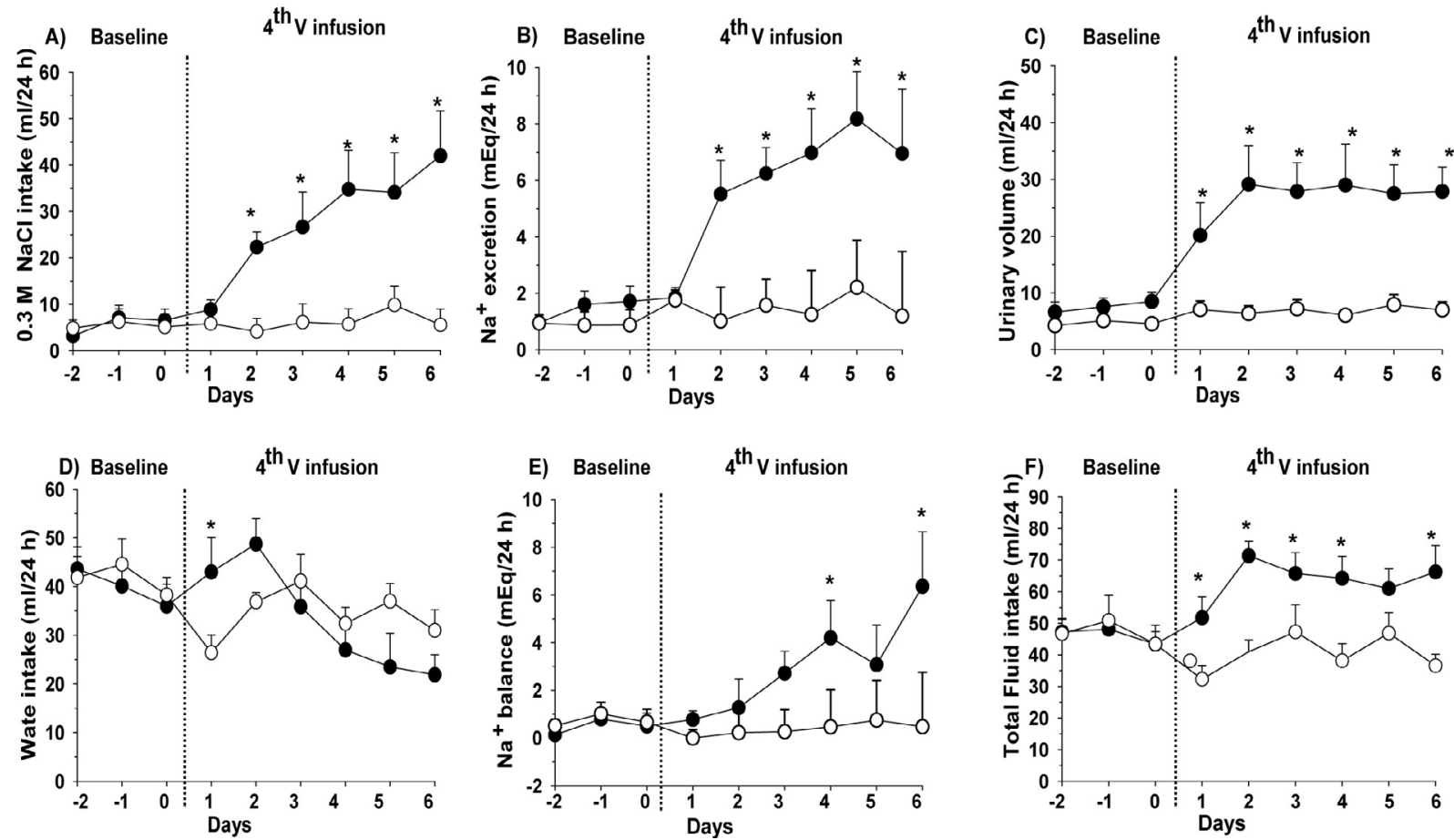

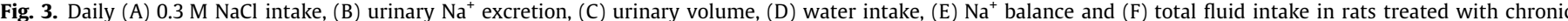

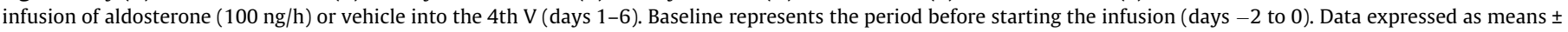
SEM.
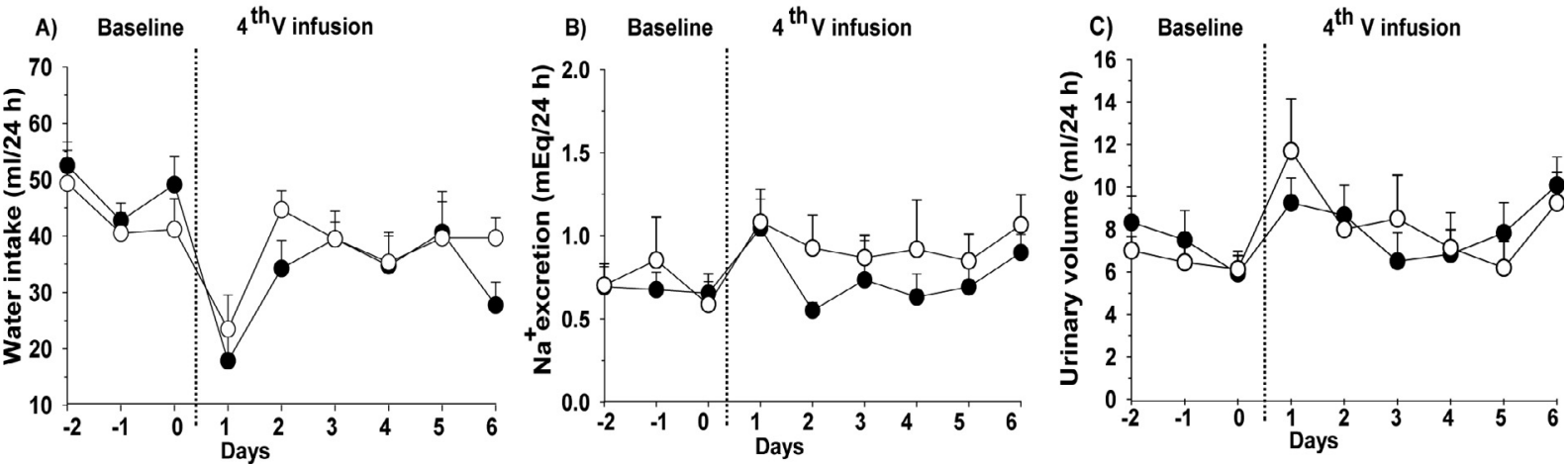

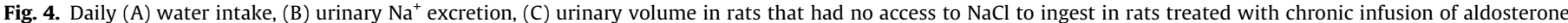
$(100 \mathrm{ng} / \mathrm{h})$ or vehicle into the 4 th $\mathrm{V}$ (days $1-6)$. Baseline represents the period before starting the infusion (days -2 to 0 ). Data expressed as means \pm SEM.

In rats that had no access to $0.3 \mathrm{M} \mathrm{NaCl}$, aldosterone infusion into the 4th $\mathrm{V}$ did not alter baroreflex responses to phenylephrine (aldosterone, $n=6$ : slope: $-1.33 \pm 0.30$, vs. vehicle, $n=4:-1.47 \pm$ $0.16 \mathrm{bpm} / \mathrm{mmHg}, \mathrm{R}=0.241$ ) (Fig. $7 \mathrm{~A}$ ) or sodium nitroprusside (slope: $-2.90 \pm 0.55$, vs. vehicle: $-5.11 \pm 1.29 \mathrm{bpm} / \mathrm{mmHg}, \mathrm{R}=$ 0.285 ) (Fig. 7B). Bradycardic responses to chemoreflex with $K C N$ activation were again attenuated $(-46 \pm 13$, vs. vehicle: $-111 \pm 4$ bpm) $[\mathrm{F}(1,8)=14.02 ; \mathrm{p}<0.05]$, without significantly changing the pressor response (Fig. $7 \mathrm{C}, \mathrm{D}$ ), whereas the hypotensive response to phenylbiguanide increased (Fig. 7C, D) $[\mathrm{F}(1,8)=$ 5.67; $\mathrm{p}<0.05$ ]. The infusion of aldosterone into the 4 th $\mathrm{V}$ in these rats again did not modify MAP ( $111 \pm 2$, vs. vehicle: $111 \pm 2 \mathrm{mmHg})$ $[\mathrm{F}(1,8)=0.04 ; \mathrm{p}>0.05]$ or $\mathrm{HR}(350 \pm 12$, vs. vehicle: $389 \pm 23 \mathrm{bpm}$ $[\mathrm{F}(1,8)=2.63 ; \mathrm{p}>0.05]$. 
Table 1

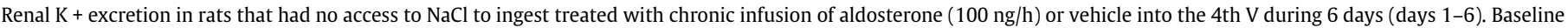
represents the period before starting the infusion (days -2 to 0 ).

\begin{tabular}{|c|c|c|c|c|c|c|c|c|c|}
\hline & -2 & -1 & 0 & 1 & 2 & 3 & 4 & 5 & 6 Days \\
\hline \multicolumn{10}{|c|}{$\mathrm{K}^{+}$excretion $(\mathrm{mEq})-0.3 \mathrm{M} \mathrm{NaCl}$ access } \\
\hline Vehicle $(n=7)$ & $2.5 \pm 0.2$ & $2.7 \pm 0.6$ & $2.5 \pm 0.1$ & $3.0 \pm 0.5$ & $3.1 \pm 0.9$ & $3.3 \pm 0.7$ & $2.4 \pm 1.1$ & $3.3 \pm 0.6$ & $2.6 \pm 0.4$ \\
\hline Aldosterone $(n=8)$ & $2.5 \pm 0.6$ & $3.06 \pm 0.6$ & $3.0 \pm 3.6$ & $3.5 \pm 0.7$ & $6.6 \pm 1.5^{*}$ & $6.7 \pm 1.1^{*}$ & $7.2 \pm 1.8^{*}$ & $6.6 \pm 1.9^{*}$ & $7.2 \pm 2.1^{*}$ \\
\hline \multicolumn{10}{|c|}{$\mathrm{K}^{+}$excretion $(\mathrm{mEq})-$ no $0.3 \mathrm{M} \mathrm{NaCl}$ access } \\
\hline Vehicle $(n=8)$ & $3.3 \pm 0.6$ & $3.0 \pm 0.7$ & $2.6 \pm 0.7$ & $3.4 \pm 0.8$ & $3.6 \pm 0.7$ & $2.5 \pm 0.4$ & $2.5 \pm 0.6$ & $3.3 \pm 0.7$ & $1.0 \pm 4.2$ \\
\hline Aldosterone $(n=6)$ & $2.9 \pm 0.3$ & $2.4 \pm 0.4$ & $2.4 \pm 0.4$ & $2.0 \pm 2.6^{*}$ & $2.1 \pm 0.3^{*}$ & $2.7 \pm 0.6$ & $2.3 \pm 0.3$ & $2.0 \pm 0.4^{*}$ & $2.5 \pm 0.2^{*}$ \\
\hline
\end{tabular}

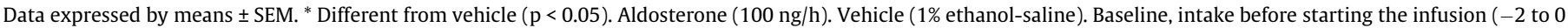
days); 4 th $\mathrm{V}$ infusion of aldosterone or vehicle ( $0-6$ days $) . n=$ number of animals. Data expressed as means $\pm S E M$.
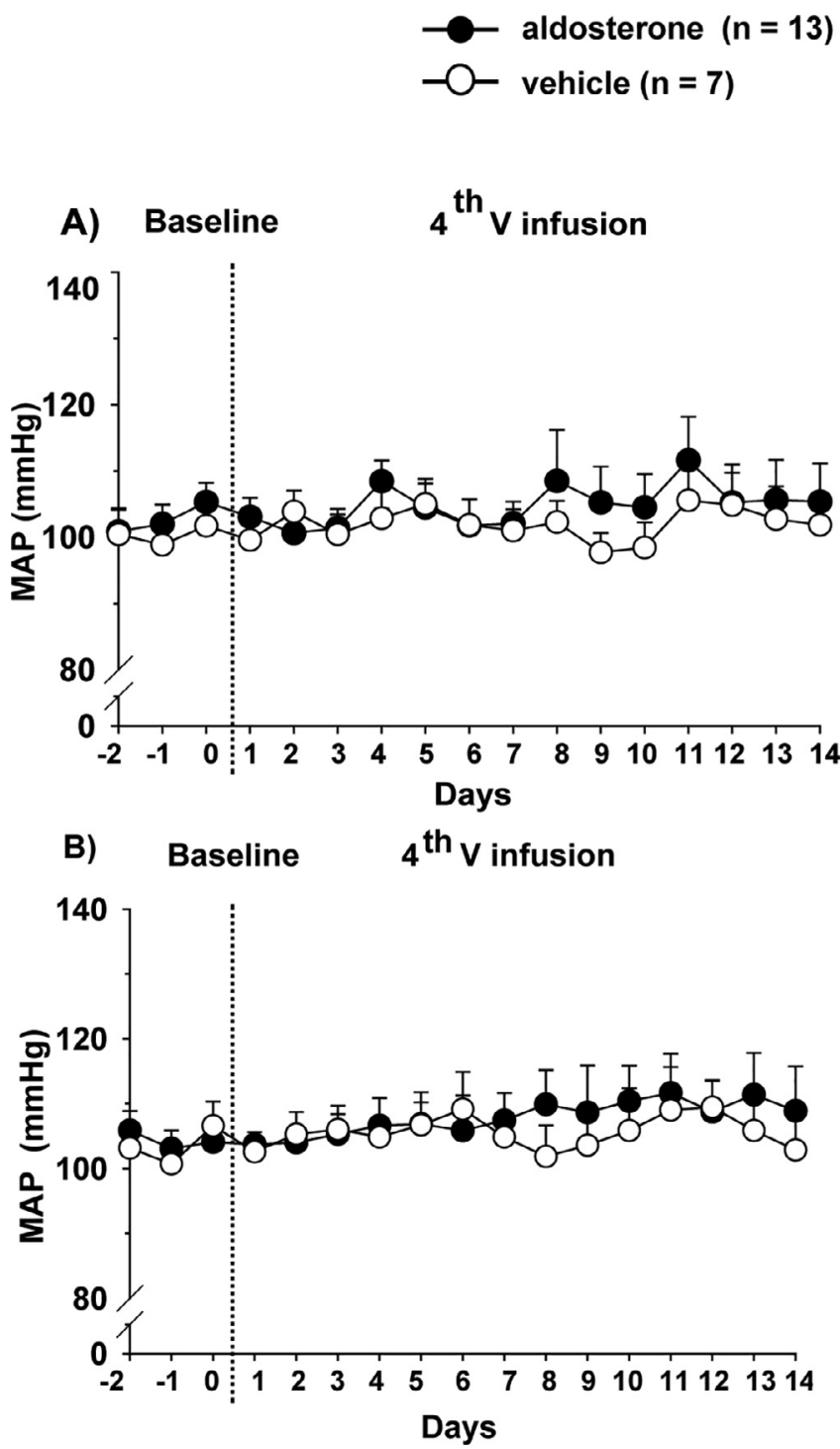

Fig. 5. Mean arterial pressure (MAP) in (A) the light and (B) dark period in rats treated with chronic infusion of aldosterone $(100 \mathrm{ng} / \mathrm{h})$ or vehicle into the 4 th $\mathrm{V}$. Baseline represents the period before starting the infusion (days -2 to 0 ). Data expressed as means \pm SEM.

\subsection{PRA in rats treated with aldosterone infusion into the 4th $\mathrm{V}$}

The PRA was measured on the 7th day of aldosterone or saline infusion into the 4 th $\mathrm{V}$ and it was not different between groups. All PRA values were less than $0.2 \mathrm{mg} / \mathrm{ml} / \mathrm{h}$.

\section{Discussion}

The present results confirm that chronic aldosterone infusion into the 4 th $\mathrm{V}$ strongly increased daily $0.3 \mathrm{M} \mathrm{NaCl}$ intake, as previously demonstrated by Formenti et al. (2013), and produced a small, inconsistent decrease in water intake. Aldosterone infusion also induced c-Fos activation in HSD2 neurons of the intermediate NTS and rostral NTS and in non-HSD2 neurons of the caudal NTS. Elevated $\mathrm{NaCl}$ intake due to 4 th $\mathrm{V}$ aldosterone infusion increased renal excretion, but rats without access to $\mathrm{NaCl}$ did not exhibit this effect, indicating that aldosterone's effect on HSD2 neurons or nonHSD2 neurons do not directly influence renal excretion. Aldosterone infusion into the 4th $\mathrm{V}$ also impaired baroreflex sensitivity in animals that had access to sodium. The bradycardic response to chemoreflex activation was reduced by aldosterone, with or without saline access, without changing baseline MAP or HR. These results suggest that HS2D neurons of the NTS are part of the mechanisms activated by aldosterone acting in the hindbrain to stimulate sodium appetite. In addition, aldosterone in the hindbrain reduces the sensitivity of the baroreflex when combined with sodium ingestion.

Neuroanatomical studies initially showed that HSD2 neurons in the NTS were activated in mineralocorticoid (DOCA) treated rats and deactivated by hypertonic $\mathrm{NaCl}$ ingestion, suggesting that these neurons might play a role in sodium appetite (Geerling and Loewy, 2006a). Behavioral studies showed that chronic infusion of aldosterone into the 4th $\mathrm{V}$ strongly increases daily sodium intake, and that sodium intake can be reduced by MR blockade or by reducing MR expression in the NTS (Formenti et al., 2013; Koneru et al., 2014). More recently, two groups found that chemogenetic activation of HSD2 neurons drives mice to consume large volumes of concentrated $0.5 \mathrm{M} \mathrm{NaCl}$ or eat salty chow (Jarvie and Palmiter, 2017; Resch et al., 2017). The present results show that the HSD2 neurons located in the NTS are activated by the same dose of aldosterone that induces sodium appetite when infused into the 4 th $\mathrm{V}$, which expands the results of previous functional and neuroanatomical studies suggesting a correlation between the activity of HSD2 neurons in the NTS and sodium appetite caused by aldosterone acting in the hindbrain. Although we know that HSD2 neurons regulate sodium appetite (Jarvie and Palmiter, 2017; Resch et al., 2017), our observation that non-HSD2 neurons also showed c-Fos expression raises the possibility that other neurons participate as well. Aldosterone could affect these neurons via G protein-coupled estrogen receptor (GPER) (Funder, 2011; Qiao et al., 2016). Alternatively, non-HSD2 neurons could be activated synaptically by HSD2 neurons. This hypothesis could be tested in ex vivo brainstem slices (Resch et al., 2017) by selectively stimulating HSD2 neurons while recording non-HSD2 neurons in the caudal NTS.

The infusion of aldosterone into the 4 th $\mathrm{V}$ produced strong natriuresis and diuresis in rats that had access to $0.3 \mathrm{M} \mathrm{NaCl}$ to ingest, yet it produced no change in urinary volume or sodium 
Table 2

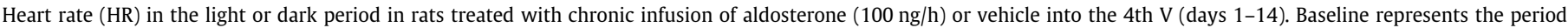
before starting the infusion (days -2 to 0 ).

\begin{tabular}{|c|c|c|c|c|c|c|c|c|c|c|c|c|c|c|c|c|c|}
\hline & -2 & -1 & 0 & 1 & 2 & 3 & 4 & 5 & 6 & 7 & 8 & 9 & 10 & 11 & 12 & 13 & 14 Days \\
\hline \multicolumn{18}{|c|}{ HR (bpm) in the light period } \\
\hline Vehicle & $345 \pm 15$ & $324 \pm 10$ & $335 \pm 6$ & $331 \pm 6$ & $345 \pm 8$ & $329 \pm 8$ & $331 \pm 9$ & $340 \pm 5$ & $352 \pm 19$ & $336 \pm 10$ & $324 \pm 12$ & $324 \pm 12$ & $316 \pm 7$ & $325 \pm 7$ & $328 \pm 10$ & $344 \pm 12$ & $353 \pm 14$ \\
\hline Aldosterone & $336 \pm 11$ & $338 \pm 9$ & $342 \pm 9$ & $328 \pm 6$ & $333 \pm 7$ & $327 \pm 10$ & $362 \pm 10$ & $334 \pm 9$ & $325 \pm 8$ & $324 \pm 5$ & $324 \pm 8$ & $340 \pm 8$ & $337 \pm 9$ & $341 \pm 13$ & $330 \pm 7$ & $323 \pm 6$ & $343 \pm 10$ \\
\hline \multicolumn{18}{|c|}{$H R(\mathrm{bpm})$ in the dark period } \\
\hline Vehicle & $392 \pm 8$ & $355 \pm 18$ & $393 \pm 9$ & $360 \pm 9$ & $377 \pm 5$ & $370 \pm 8$ & $377 \pm 15$ & $389 \pm 8$ & $411 \pm 16$ & $387 \pm 7$ & $375 \pm 9$ & $378 \pm 8$ & $380 \pm 7$ & $387 \pm 6$ & $383 \pm 5$ & $391 \pm 3$ & $390 \pm 12$ \\
\hline Aldosterone & $382 \pm 12$ & $372 \pm 9$ & $388 \pm 8$ & $363 \pm 8$ & $362 \pm 7$ & $365 \pm 8$ & $392 \pm 10$ & $352 \pm 19$ & $379 \pm 8$ & $375 \pm 7$ & $386 \pm 16$ & $376 \pm 8$ & $379 \pm 8$ & $367 \pm 8$ & $391 \pm 9$ & $384 \pm 10$ & $381 \pm 8$ \\
\hline
\end{tabular}

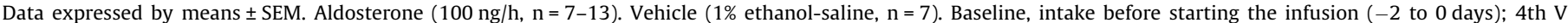
infusion of aldosterone or vehicle (0-14 days).

Table 3

Daily $0.3 \mathrm{M} \mathrm{NaCl}$ and water intake produced by chronic infusion of aldosterone into the 4 th $\mathrm{V}$ over a 14 day period.

\begin{tabular}{|c|c|c|c|c|c|c|c|c|c|c|c|c|c|c|c|c|c|}
\hline & -2 & -1 & 0 & 1 & 2 & 3 & 4 & 5 & 6 & 7 & 8 & 9 & 10 & 11 & 12 & 13 & 14 Days \\
\hline \multicolumn{18}{|c|}{$0.3 \mathrm{M} \mathrm{NaCl}$ intake $(\mathrm{ml})$} \\
\hline Vehicle & $8 \pm 4$ & $11 \pm 5$ & $5 \pm 1$ & $4 \pm 1$ & $8 \pm 2$ & $9 \pm 2$ & $9 \pm 2$ & $10 \pm 3$ & $5 \pm 1$ & $10 \pm 3$ & $9 \pm 2$ & $8 \pm 4$ & $11 \pm 5$ & $5 \pm 1$ & $6 \pm 2$ & $7 \pm 2$ & $5 \pm 1$ \\
\hline Aldosterone & $9 \pm 1$ & $11 \pm 2$ & $12 \pm 2$ & $15 \pm 3^{*}$ & $20 \pm 2^{*}$ & $28 \pm 4^{*}$ & $29 \pm 7^{*}$ & $31 \pm 7^{*}$ & $35 \pm 6^{*}$ & $29 \pm 8^{*}$ & $30 \pm 9 *$ & $31 \pm 9^{*}$ & $35 \pm 9^{*}$ & $35 \pm 11^{*}$ & $37 \pm 11^{*}$ & $39 \pm 13^{*}$ & $43 \pm 14$ \\
\hline \multicolumn{18}{|c|}{ Water intake $(\mathrm{ml})$} \\
\hline Vehicle & $37 \pm 4$ & $37 \pm 3$ & $47 \pm 4$ & $23 \pm 7$ & $45 \pm 3$ & $42 \pm 6$ & $39 \pm 4$ & $45 \pm 4$ & $38 \pm 3$ & $36 \pm 4$ & $36 \pm 6$ & $34 \pm 5$ & $37 \pm 5$ & $36 \pm 7$ & $46 \pm 3$ & $40 \pm 6$ & $41 \pm 5$ \\
\hline Aldosterone & $36 \pm 4$ & $41 \pm 3$ & $39 \pm 4$ & $28 \pm 4$ & $32 \pm 2^{*}$ & $35 \pm 3$ & $29 \pm 3$ & $27 \pm 3^{*}$ & $38 \pm 4$ & $32 \pm 5$ & $22 \pm 4^{*}$ & $21 \pm 5$ & $29 \pm 7$ & $28 \pm 6$ & $25 \pm 4^{*}$ & $28 \pm 6$ & $29 \pm 4$ \\
\hline
\end{tabular}

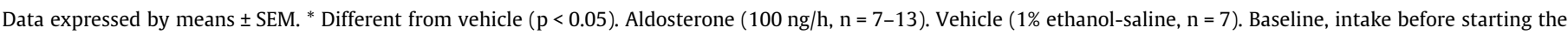
infusion ( -2 to 0 days); 4 th $\mathrm{V}$ infusion of aldosterone or vehicle (0-14 days).

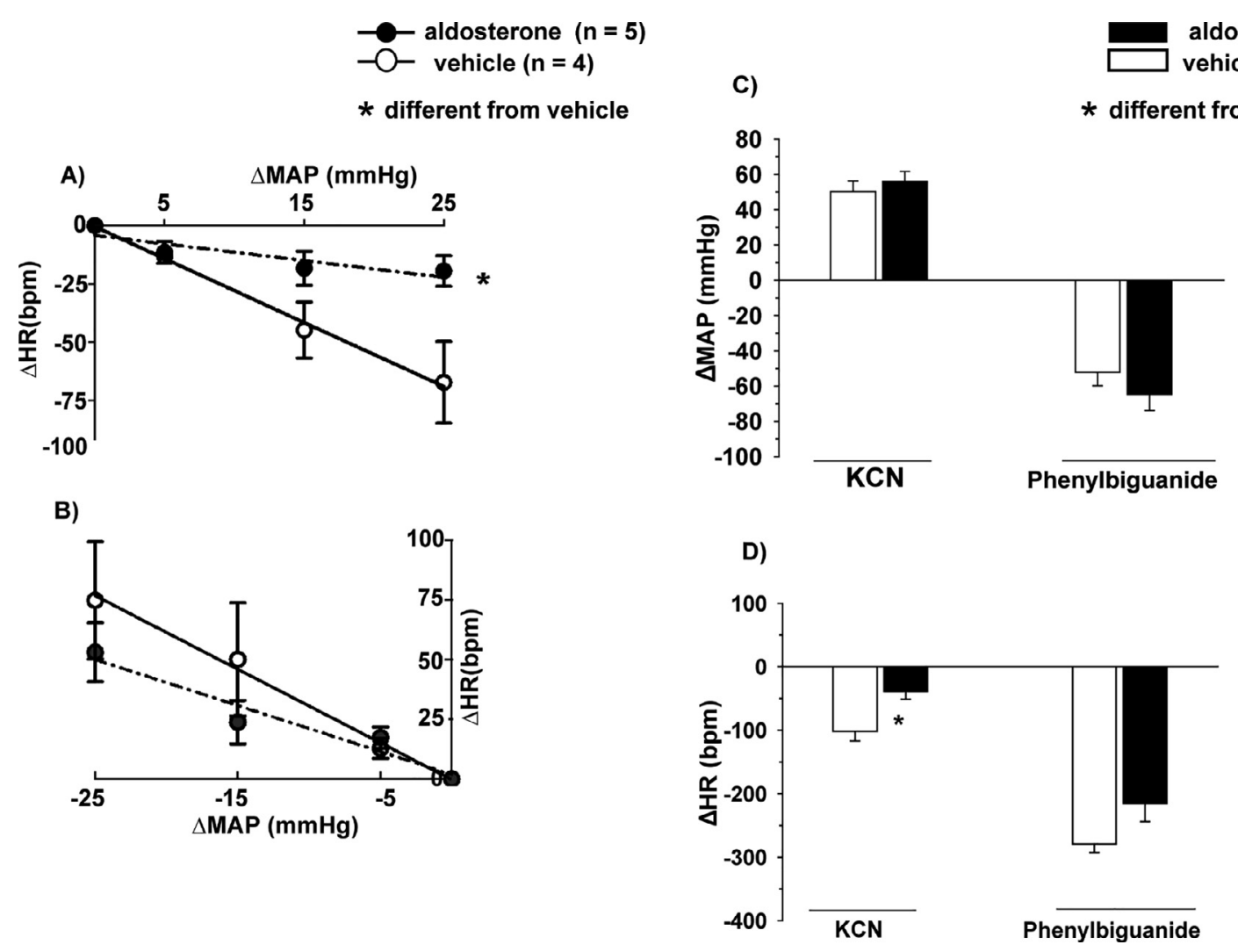

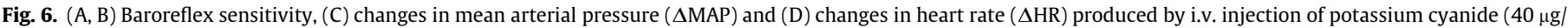

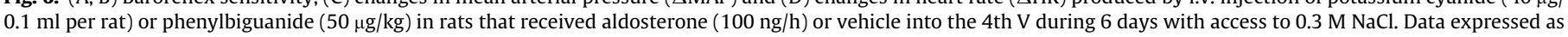
means \pm SEM.

excretion if $\mathrm{NaCl}$ solution was not available to ingest, suggesting that aldosterone into the 4 th $\mathrm{V}$ produces no direct effect on renal sodium or water excretion. These results suggest that infusing aldosterone into the 4 th $\mathrm{V}$ is primarily natriorexigenic, whereas natriuresis and diuresis occur secondarily to excess ingestion of $0.3 \mathrm{M} \mathrm{NaCl}$ produced by the infusion of aldosterone. We also evaluated potassium excretion, which was higher in aldosterone treated animals that had access to $0.3 \mathrm{M} \mathrm{NaCl}$, possibly due an increase 
-0 aldosterone $(n=5)$
-0 vehicle $(n=4)$

* different from vehicle
C)

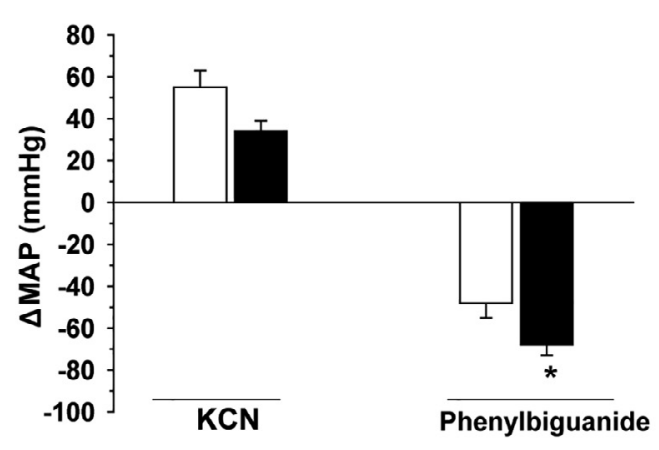

D)

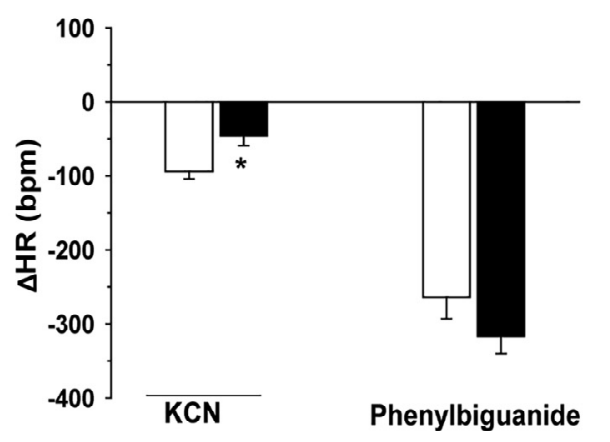

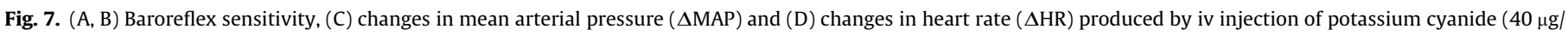

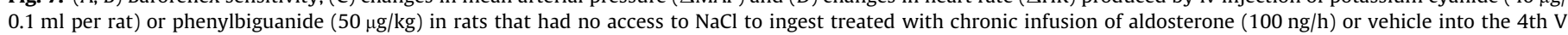
during 6 days. Data expressed as means \pm SEM.

in urinary flow (Welling, 2013). However, in animals without access to sodium, kaliuresis varied across time in both groups, which we cannot explain, but could have to do with subtle changes in potassium handling not captured in the present dataset.

In spite of the strong ingestion of hypertonic $\mathrm{NaCl}$ induced by infusing aldosterone into the 4 th $\mathrm{V}$, water intake did not change or was variably reduced when compared to control group, confirming that aldosterone specifically stimulates sodium intake. Chronic infusion of aldosterone with $0.3 \mathrm{M} \mathrm{NaCl}$ ingestion also produced a tendency of positive sodium balance that was different from vehicle on the 4th and 6th day of infusion, suggesting that urinary excretion may not completely compensate for the increased sodium intake.

Besides increasing sodium appetite, aldosterone infusion into the 4th $\mathrm{V}$ modified reduced baroreflex sensitivity when the animals had sodium hypertonic $\mathrm{NaCl}$ solution available. However, it is difficult to know exactly whether their increased sodium intake per se or the combined action of with aldosterone infusion into the 4 th $\mathrm{V}$ was responsible for the change in baroreflex sensitivity. Sodium intake produces changes in baroreflex sensitivity in humans (Creager et al., 1991). In addition, Nakamura and colleagues (Nakamura et al., 1988) demonstrated that DOCA-salt loaded rats have the central component of baroreflex impaired. Moreover, in DOCA-salt hypertensive rats, chorthalidone treatment, which reduces plasma sodium, normalizes baroreceptor responses (Bissoli et al., 2000).

Although we showed that sodium intake is important to change baroreflex sensitivity in 4th $\mathrm{V}$ aldosterone-treated animals, others showed that peripherally administrated aldosterone has an independent effect. Infusion of aldosterone in isolated carotid sinus acutely or subcutaneous infusion chronically reduced baroreceptor activity in dogs, a response prevented by previous infusion of the MR receptor antagonist spironolactone (Wang et al., 1992; Wang, 1994). In healthy, normotensive volunteers, acute i.v. infusion of aldosterone also impaired the baroreflex, with marked decrease in the bradycardic response to phenylephrine (Yee and Struthers, 1998). It is difficult to know if the change in baroreflex produced by aldosterone is due to the activity of HSD2 or non-HSD2 neurons. In the present study, aldosterone was infused close to the NTS, an area that receives baroreceptor afferents and where HSD2 neurons are located (Geerling et al., 2006b; Guyenet, 2006; Roland et al., 1995). It is possible that aldosterone acting on HSD2 neurons in the NTS indirectly affects the activity of other NTS neurons that process baroreceptor signals, via local synaptic connection in the NTS.

Aldosterone infused chronically into the lateral ventricle increased MAP in rats and dogs, independent of sodium retention (Gomez-Sanchez et al., 1990; Peysner et al., 1990), whereas here aldosterone infused into the 4 th $\mathrm{V}$ produced no change in MAP and HR, despite of a tendency to increase sodium retention. Our data complement the recent finding that HSD2 neuron chemogenetic activation does not change blood pressure or heart rate (Resch et al., 2017). On the other hand, Evans and colleagues (Evans et al., 2016) showed an increase in blood pressure in mice with Hsd11b2 expression eliminated from the brain when these mice were given saline to drink. Besides the possibility of a species difference between mice and rats, a potentially important distinction is the breeding strategy in that study. Evans et al. crossed Nestin-Cre transgenic mice with their floxed Hsd11b2 strain, which should eliminate the developmental expression of Hsd11b2 
in many brain regions outside the NTS (Naray-Fejes-Toth and Fejes-Toth, 2007; Robson et al., 1998) impeding neurogenesis by exposing cells to glucocorticoids (Holmes et al., 2006a; Noguchi et al., 2008). Developmental elimination of Hsd11b2 reduces adult cerebellar size (Holmes et al., 2006b), but the potential cardiovascular consequences for central autonomic neurons are unknown. Although in the hindbrain it appears that MR and HSD2 neurons may not modulate blood pressure, Gomes Sanchez (GomezSanchez, 1986), infused aldosterone into the lateral ventricle at 5 $\mathrm{ng} / \mathrm{h}$ in nephrotomized rats with only saline available to drink and was found an increase in systolic blood pressure when measured by tail-cuff. If the kidney was not removed, a higher dose $(45 \mathrm{ng} / \mathrm{h})$ was necessary to increase blood pressure (Gomez Sanchez, 1988).

Separately, Van den Berg et al. (1994) demonstrated a depressor effect of injecting the MR antagonist RU28318 in normotensive, spontaneous hypertensive, and DOCA-salt hypertensive rats. This depressor effect did not occur in free-moving rats, and required warming and restraint-stress conditions mimicking tail-cuff measurement of BP (Van den Berg et al., 1994). Rahmouni showed that this depressor effect of RU283818 depends on renal innervation (Rahmouni et al., 1999; Rahmouni et al., 2002). MR activation in the AV3V region of the hypothalamus was proposed to explain the increase of arterial pressure by aldosterone infused into the lateral ventricles (Gomez-Sanchez, 1986), but the cell types, locations, and mechanisms remain unclear.

In the present work we infused a low dose of aldosterone (100 $\mathrm{ng} / \mathrm{h}$ ) and we exclude the action of aldosterone on other brain structures based on the fact that infusion of aldosterone into the lateral ventricle at the same concentration infused into the 4 th $\mathrm{V}$ produces no sodium intake (Formenti et al., 2013). We also exclude the likelihood of a peripheral action of our 4th $\mathrm{V}$ aldosterone infusions, based on a prior dose-response study on peripheral administration of aldosterone (Garwitz and Jones, 1982). Subcutaneous infusion required at least $2.5 \times$ more aldosterone $(250 \mathrm{ng} / \mathrm{h})$ to produce a statistically significant rise in the plasma concentration of aldosterone, and at least $5 \times$ more $(500-1000 \mathrm{ng} / \mathrm{h})$ to produce a statistically significant increase in saline ingestion, relative to the dose we infused into the 4 th $\mathrm{V}(100 \mathrm{ng} / \mathrm{h})$. Some portion of our 4 th $\mathrm{V}$ aldosterone infusion probably did escape into the periphery, but based on these dose-response data the quantity would not be sufficient to change sodium appetite or even plasma aldosterone significantly, even if we had infused it peripherally.

In conclusion, the present results suggest that aldosterone activates HSD2 neurons in the NTS to produce a natriorexigenic effect, which is the cause, not a consequence of changes in renal excretion. In addition, the reduction in baroreflex sensitivity produced by aldosterone and sodium intake is not associated with changes in baseline blood pressure or heart rate. Future investigations are necessary to provide information on whether HSD2 neurons are involved in other cardiovascular and behavioral functions.

\section{Experimental procedure}

\subsection{Animals}

Male Holtzman rats weighing 280-320 g were used housed individually in stainless steel cages in a room with controlled temperature $\left(23 \pm 2{ }^{\circ} \mathrm{C}\right)$ and humidity $(55 \pm 10 \%)$. Lights were on from 7:00 am to 7:00 pm. Biobase rat chow (Águas Frias, SC, Brazil) and tap water were available ad libitum. Rats also had access to $0.3 \mathrm{M}$ $\mathrm{NaCl}$ ad libitum or for $2 \mathrm{~h} /$ day depending on the protocol. The experimental protocols used in the present study were approved by the Ethical Committee for Animal Care and Use from the Dentistry School of Araraquara - UNESP.

\subsection{Brain surgery}

The animals were anesthetized with ketamine $(80 \mathrm{mg} / \mathrm{kg})$ and xylazine $(7 \mathrm{mg} / \mathrm{kg}$ ) intraperitoneally (i.p.) and placed in a Kopf stereotaxic instrument. The skull was positioned with bregma and lambda at the same horizontal level. An intracerebral 23-gauge stainless steel guide cannula was implanted in the 4 th $\mathrm{V}$ according to the following coordinates: $12.9 \mathrm{~mm}$ caudal to bregma, in the midline and $4.8 \mathrm{~mm}$ below the surface of the skull. The tips of the cannulas were positioned at a point $2 \mathrm{~mm}$ above the 4 th $\mathrm{V}$. The cannulas were fixed to the cranium using dental acrylic resin and jeweler screws. Post-surgery, animals received an intramuscular injection of penicillin (30,000 IU) and a subcutaneous (s.c.) injection of the analgesic Ketoflex (ketoprofen 1\%, $0.03 \mathrm{ml} / \mathrm{rat}$ ).

After the surgery, rats were allowed to recover for one week before starting water and $\mathrm{NaCl}$ intake tests or arterial pressure recordings.

\subsection{Intracerebroventricular infusions}

The infusions were performed using osmotic mini-pumps (model 2001, Durect Corp. Cupertino, CA) filled with aldosterone ( $100 \mathrm{ng} / \mu \mathrm{l}$, dissolved in $1 \%$ ethanol in $0.9 \% \mathrm{NaCl}$ ) or vehicle. The osmotic mini-pumps were incubated for at least $24 \mathrm{~h}$ in saline at room temperature prior to the implantation in the scapular region under $1 \%$ halothane anesthesia. For the infusions into the 4 th $\mathrm{V}$, the pumps were connected with polyethylene tubing to a 30-gauge stainless steel injector cannula $(2 \mathrm{~mm}$ longer than the guide cannula).

\subsection{Water and $0.3 \mathrm{M} \mathrm{NaCl}$ intake and urine analyses}

Rats chronically infused with aldosterone $(100 \mathrm{ng} / \mu \mathrm{l} / \mathrm{h})$ or vehicle were housed in metabolic cages with water and food ad libitum. Two groups also had access to $0.3 \mathrm{M} \mathrm{NaCl}$ solution ad libitum. Water and $0.3 \mathrm{M} \mathrm{NaCl}$ were provided from burettes with $1 \mathrm{ml}$ divisions that were fitted with metal drinking spouts. Urine samples were collected in $0.1 \mathrm{ml}$ graduated polypropylene tubes, and urinary volume was measured. Sodium and potassium urinary concentration was measured by an ion-specific electrode (Nova Biomedical Analyser, model Nova 1) and the amount of sodium and potassium in the urine was determined by the product of urine volume times the concentration of each ion in the urine. Water and $0.3 \mathrm{M} \mathrm{NaCl}$ intake and urine samples were measured on a 24-h basis for nine days.

\subsection{Baroreflex, chemoreflex and cardiopulmonary reflex tests}

Six days after inserting mini-pumps, animals were anesthetized with ketamine ( $80 \mathrm{mg} / \mathrm{kg}$ of body weight i.p.) and xylazine $(7 \mathrm{mg} /$ $\mathrm{kg}$ of body weight i.p.), and polyethylene tubing (PE-10 connected to a PE-50) was inserted into the abdominal aorta through the femoral artery on the day before the experiments. Polyethylene tubing was also inserted into the femoral vein for drug administration. These catheters were tunneled subcutaneously and exposed on the back of the rat to allow access in awake rats. To record pulsatile arterial pressure, mean arterial pressure (MAP) and heart rate (HR), the arterial catheter was connected to a Stathan Gold (P23 Db) pressure transducer connected with an ETH-200 amplifier (CB Sciences, Dover, NH) and to a PowerLab data acquisition system (ADInstruments, Dunedin, New Zealand).

We evaluated baroreflex sensitivity with i.v. phenylephrine (40 $\mu \mathrm{g} / \mathrm{kg}$ ) and sodium nitroprusside $(30 \mu \mathrm{g} / \mathrm{kg})$. We analyzed one second mean $\mathrm{HR}$ values in response to $10 \mathrm{mmHg}$ incremental or decremental changes in MAP, starting at $0 \mathrm{mmHg}$ up to a maximal change of 25 or $-25 \mathrm{mmHg}$. The values were plotted and we used 
GraphPad to perform a linear regression for each animal. The regression coefficient (slope) was used to analyze baroreflex sensitivity as the increase or decrease of HR across changes in mean arterial pressure (MAP).

To test chemoreflex and cardiopulmonary reflex, potassium cyanide ( $\mathrm{KCN}, 40 \mu \mathrm{g} / 0.1 \mathrm{ml} / \mathrm{rat}$ ) and phenylbiguanide $(50 \mu \mathrm{g} / \mathrm{kg}$ ) were administrated i.v., respectively. The interval between i.v. injections was $5 \mathrm{~min}$.

\subsection{Chronic arterial pressure and heart rate recordings}

A telemetry method was used to record arterial pressure and heart rate chronically. Using aseptic techniques, a laparotomy was performed and the catheter of the pressure telemetry transmitter (Model TA11PAC40, Data Sciences International, New Brighton, MN) was inserted into the descending abdominal aorta, distal to the kidneys according to the manufacturer's instructions. The catheter was fixed in the aorta with cyanoacrylate adhesive and the transmitter was secured to the abdominal wall with sutures. Mean daily 24-h blood pressure (BP) and heart rate data were derived from the average BP measured by bursts of 10 s every 5 min using the software (Dataquest 4.0) provided by the manufacturer.

\subsection{Plasma renin activity}

Trunk blood was collected after decapitation for determination of plasma renin activity (PRA). Samples for PRA were collected in tubes pre-refrigerated at $0{ }^{\circ} \mathrm{C}$ containing sodium EDTA $(2 \mathrm{mg} / \mathrm{ml}$ of blood) to obtain plasma. All samples were centrifuged (3000 rpm for $20 \mathrm{~min}$ at $4{ }^{\circ} \mathrm{C}$ ) then stored at $-20^{\circ} \mathrm{C}$.

One hundred microliters of the plasma sample were mixed with $200 \mathrm{ml}$ of $0.2 \mathrm{M}$ Tris- $\mathrm{HCl}$ buffer $\mathrm{pH} 7.4,20 \mathrm{ml}$ of $48 \mathrm{mM}$ of $8-\mathrm{OH}-$ quinoleine and $10 \mathrm{ml}$ of $161 \mathrm{mM}$ phenylmethylsulfonyl fluoride and was incubated at $37^{\circ} \mathrm{C}$ for $3 \mathrm{~h}$. Blanks were prepared by incubating plasma samples in the same conditions at $4{ }^{\circ} \mathrm{C}$. After incubation, the amount of angiotensin I generated from angiotensinogen was determined by radioimmunoassay, utilizing rabbit antibody for angiotensin I from the Maia Biodata Kit for renin activity (Biochem Imunosystem).

\subsection{Immunohistochemistry}

Animals were deeply anesthetized with sodium thiopental ( $70 \mathrm{mg} / \mathrm{kg}$ body weight i.p.), transcardially perfused with $0.9 \%$ saline followed by $4 \%$ paraformaldehyde and brains were prepared as detailed before (Melo et al., 2015). Four sets of axial sections $(40 \mu \mathrm{m})$ of the brainstem and forebrain were sectioned on a cryostat (Leica, CM1850, Wetzlar, Hesse, Germany). One of the sets of the brain sections was pre-incubated for $15 \mathrm{~min}$ in a blocking solution composed of $10 \%$ ( $\mathrm{vol} / \mathrm{vol}$ ) normal horse serum (NHS, Sigma, St Louis, MO, USA) and 0.3\% (vol/vol) Triton X-100 (Sigma) in $0.1 \mathrm{M}$ PBS followed by rinses in PBS $(3 \times 10 \mathrm{~min})$. Subsequently, sections were incubated with a sheep anti-HSD2 primary antibody (1:15,000, Millipore) and rabbit anti-c-Fos (1:1,500, Santa Cruz Biotechnology), in PBS containing $1 \%$ (vol/vol) NHS and $0.3 \%$ Triton-X-100 for $48 \mathrm{~h}$ at $4{ }^{\circ} \mathrm{C}$. Sections were rinsed in PBS between the steps. After this, a 1-h incubation in biotinylated horse antigoat IgG (1:500, Vector Laboratories, Burlingame) was followed by 1 -h incubation in Streptavidin Alexa Fluor 488 conjugate and donkey anti-rabbit Alexa Fluor 594 (both 1:500; Life Technologies). Then, the sections were mounted onto slides in $0.5 \%$ gelatin and allowed to air-dry for 10-15 min before being cover slipped using antifade fluorescent mounting solution (Fluoromount, SigmaAldrich, St. Louis, MO, USA). The sections were examined in a fluorescence microscope (Leica DM5500 B, Wetzlar, Hessen, Germany) with the appropriated filters.

Fos-IR nuclei and the presence of HSD2 neurons were counted in one section of each area previously defined, in each case the section that appeared to have the greatest number of Fos-positive nuclei. Neuroanatomical sites were identified according to Paxinos and Watson's Atlas (Paxinos and Watson, 1997).

For assessing c-Fos in HSD2 neurons in the nucleus of the solitary tract (NTS), $20 \mu \mathrm{m}$ z-stacks (containing 20 images) were collected through c-Fos and HSD2 stained sections at 20x magnification and counted manually on a computer using Leica software (Application Suite Advanced Fluorescence, LAS X).

\subsection{Histology}

At the end of the experiments, all animals not used for immunofluorescence received through a single injection of $2 \%$ Evans blue solution $(2 \mu \mathrm{l})$ into the 4 th $\mathrm{V}$. They were then deeply anesthetized with sodium thiopental ( $60 \mathrm{mg} / \mathrm{kg}$ of body weight) and perfused transcardially with $10 \%$ formalin. The brains were removed and fixed in $10 \%$ formalin for at least 2 days. Following post fixation, the brains were frozen, cut in $60 \mu \mathrm{m}$ sections, Giemsa-stained and analyzed by light microscopy to confirm the central sites of the injections. Forty-four animals did not have Evans blue in the 4th $\mathrm{V}$ or their acrylic cement detached during the experiment, and these animals were excluded from further analyses.

\subsection{Statistical analysis}

The results were analyzed by two-way ANOVA with treatments and times as factors or one-way ANOVA. In all the cases, ANOVA was followed by Newman-Keuls test. For c-Fos data, a $t$-test was used to analyze differences between groups. Differences were considered significant at $\mathrm{p}<0.05$.

\subsection{Experimental protocols}

4.11.1. Quantification of c-Fos and HSD2 expression in animals treated with aldosterone or vehicle infusion into the 4 th $\mathrm{V}$

Rats with cannulas implanted into the 4 th $\mathrm{V}$ were used. They had free access to water and food, whereas $0.3 \mathrm{M} \mathrm{NaCl}$ was offered during $2 \mathrm{~h} /$ day at 2:00 pm in the course of 8 days. The infusions of vehicle or aldosterone $(100 \mathrm{ng} / \mu \mathrm{l} / \mathrm{h})$ into the 4 th $\mathrm{V}$ started 3 days after the access to $0.3 \mathrm{M} \mathrm{NaCl}$.

On the sixth day after the beginning of the infusion, at 2:00 pm, animals were deeply anesthetized with sodium thiopental $(70 \mathrm{mg} /$ $\mathrm{kg}$ body weight ip) and had the brains removed and the number of c-Fos and HSD2 expression was quantified in different sites of the brain by immunohistochemistry procedures. On the day of the perfusion the animals had no access to $0.3 \mathrm{M} \mathrm{NaCl}$.

\subsubsection{Daily water and $0.3 \mathrm{M} \mathrm{NaCl}$ intake, renal excretion and} cardiovascular reflexes in rats treated with aldosterone infused into the 4th $V$

Rats maintained in metabolic cages with access to water, $0.3 \mathrm{M} \mathrm{NaCl}$ and food ad libitum received chronic infusion of aldosterone $(100 \mathrm{ng} / \mu \mathrm{l} / \mathrm{h})$ or vehicle into the 4 th $\mathrm{V}$. Daily ingestion of water and $0.3 \mathrm{M} \mathrm{NaCl}$ was recorded continuously for a 10 days period (control period of 3 days before starting the infusion of aldosterone or vehicle, 7 days of continuous infusion of aldosterone or vehicle). Urine volume was measured and urine samples to measure the concentration of sodium and potassium were collected daily.

At the end of the 6th day of aldosterone or vehicle infusion into the 4 th $\mathrm{V}$, catheters were inserted into the femoral artery and vein to record MAP and HR and for drug administration, respectively. 
MAP and HR were recorded $24 \mathrm{~h}$ after the surgery and the reflexes were tested with i.v. injections of phenylephrine $(5 \mu \mathrm{g} / \mathrm{kg}$ body weight), sodium nitroprusside $(30 \mu \mathrm{g} / \mathrm{kg}$ body weight), KCN $(40 \mu \mathrm{g} / 0.1 \mathrm{ml} / \mathrm{rat})$ and phenylbiguanide $(50 \mu \mathrm{g} / \mathrm{kg}$ body weight). The injection time did not last more than $30 \mathrm{~s}$ and interval between two i.v. injections was 5 min.

The same protocol described above was repeated in another two groups of animals chronically infused with aldosterone (100 $\mathrm{ng} / \mu \mathrm{l} / \mathrm{h}$ ) or vehicle into the 4 th $\mathrm{V}$, except that these animals had no access to $0.3 \mathrm{M} \mathrm{NaCl}$ to ingest.

\subsubsection{Chronic telemetry arterial pressure and heart rate in rats} treated with aldosterone into the 4th $\mathrm{V}$

Rats implanted with telemetry probes were maintained in polypropylene boxes with access to water, $0.3 \mathrm{M} \mathrm{NaCl}$ and food ad libitum and received chronic infusion of aldosterone $(100 \mathrm{ng} / \mu \mathrm{l} / \mathrm{h})$ or vehicle into the 4 th $\mathrm{V}$. Daily ingestion of water and $0.3 \mathrm{M} \mathrm{NaCl}$, MAP and HR were recorded continuously for a period of 17 days (control period of 3 days before starting the infusion of aldosterone or vehicle, 14 days of continuous infusion of aldosterone or vehicle).

\subsubsection{PRA in rats treated with aldosterone infusion into the 4 th $V$}

Rats with cannulas implanted into the 4 th $\mathrm{V}$ had free access to water, food and $0.3 \mathrm{M} \mathrm{NaCl}$. Daily ingestion of water and $0.3 \mathrm{M}$ $\mathrm{NaCl}$ was recorded continuously for 10 days (control period of 3 days before starting the infusion of aldosterone or vehicle, 7 days of continuous infusion of aldosterone or vehicle). On the 7th day of the infusion, the animals were decapitated and had blood collected for the measurement of PRA.

\section{Author contributions}

Conception and format of the paper was made by SG and MRS. Acquisition, analysis, or interpretation of data was made by SG, MRS, GMFAF, JCG, JVM and EC. SG drafted the article and MRM, GMFAF, JCG, JVM and EC revised it critically for important intellectual content. All authors approved the final version of the manuscript, agree to be accountable for all aspects of the work in ensuring that questions related to the accuracy or integrity of any part of the work are appropriately investigated and resolved. All persons designated as authors qualify for authorship, and all those who qualify for authorship are listed.

\section{Funding}

This research was supported by Conselho Nacional de Pesquisa (CNPq), Fundação de Amparo à Pesquisa do Estado de São Paulo (FAPESP 2013/00026-0; FAPESP 2015/23467-7; 2018/04134-5), PROPE-UNESP.

\section{Acknowledgments}

The authors thank Silvana A. D. Malavolta and Carla Molina for secretarial assistance and Mikail Douglas dos Santos and Ana V. Oliveira for animal care. We also thank the Laboratory of Confocal Fluorescence Microscopy from School of Dentistry, Sao Paulo State University, UNESP, Araraquara, by availability of utilization the Confocal Fluorescence Microscope. We also thank Dr. Wills K. Samson (Saint Louis University) and Mark W. Chapleau (University of Iowa) for the suggestions to improve the writing and baroreflex analyses.

\section{References}

Bissoli, N.S., Cicilini, M.A., Vasquez, E.C., Cabral, A.M., 2000. The diuretic chlorthalidone normalizes baroreceptor and Bezold-Jarisch reflexes in DOCAsalt hypertensive rats. Pharmacol. Res. 41, 483-491.

Booth, R.E., Johnson, J.P., Stockand, J.D., 2002. Aldosterone. Adv. Physiol. Educ. 26, 820.

Cooney, A.S., Fitzsimons, J.T., 1996. Increased sodium appetite and thirst in rat induced by the ingredients of liquorice, glycyrrhizic acid and glycyrrhetinic acid. Regul. Pept. 66, 127-133.

Creager, M.A., Roddy, M.A., Holland, K.M., Hirsch, A.T., Dzau, V.J., 1991. Sodium depresses arterial baroreceptor reflex function in normotensive humans. Hypertension 17, 989-996.

Daniels, D., Mietlicki, E.G., Nowak, E.L., Fluharty, S.J., 2009. Angiotensin II stimulates water and $\mathrm{NaCl}$ intake through separate cell signalling pathways in rats. Exp. Physiol. 94, 130-137.

Dundore, R.L., Wurpel, J.N., Balaban, C.D., Keil, L.C., Severs, W.B., 1984. Central effects of aldosterone infused into the rat subcommissural organ region. Neurosci. Res. 1, 341-351.

Evans, L.C., Ivy, J.R., Wyrwoll, C., McNairn, J.A., Menzies, R.I., Christensen, T.H., AlDujaili, E.A., Kenyon, C.J., Mullins, J.J., Seckl, J.R., Holmes, M.C., Bailey, M.A., 2016. Conditional deletion of Hsd11b2 in the brain causes salt appetite and hypertension. Circulation 133, 1360-1370.

Fitzsimons, J.T., 1998. Angiotensin, thirst, and sodium appetite. Physiol. Rev. 78, 583-686.

Formenti, S., Bassi, M., Nakamura, N.B., Schoorlemmer, G.H., Menani, J.V., Colombari, E., 2013. Hindbrain mineralocorticoid mechanisms on sodium appetite. Am. J. Physiol. Regul. Integr. Comp. Physiol. 304, R252-R259.

Funder, J.W., 2011. GPR30, mineralocorticoid receptors, and the rapid vascular effects of aldosterone. Hypertension 57, 370-372.

Garwitz, E.T., Jones, A.W., 1982. Aldosterone infusion into the rat and dosedependent changes in blood pressure and arterial ionic transport. Hypertension 4, 374-381.

Geerling, J.C., Loewy, A.D., 2006c. Aldosterone-sensitive neurons in the nucleus of the solitary: efferent projections. J. Comp. Neurol. 498, 223-250.

Geerling, J.C., Loewy, A.D., 2006b. Aldosterone-sensitive neurons in the nucleus of the solitary tract: bidirectional connections with the central nucleus of the amygdala. J. Comp. Neurol. 497, 646-657.

Geerling, J.C., Loewy, A.D., 2007. Sodium depletion activates the aldosteronesensitive neurons in the NTS independently of thirst. Am. J. Physiol. Regul. Integr. Comp. Physiol. 292, R1338-R1348.

Geerling, J.C., Kawata, M., Loewy, A.D., 2006b. Aldosterone-sensitive neurons in the rat central nervous system. J. Comp. Neurol. 494, 515-527.

Geerling, J.C., Engeland, W.C., Kawata, M., Loewy, A.D., 2006a. Aldosterone target neurons in the nucleus tractus solitarius drive sodium appetite. J. Neurosci. 26, 411-417.

Geerling, J.C., Loewy, A.D., 2006a. Aldosterone-sensitive NTS neurons are inhibited by saline ingestion during chronic mineralocorticoid treatment. Brain Res. 1115, 54-64.

Gomez Sanchez, E.P., 1988. Dose-response studies of intracerebroventricular infusion of aldosterone in sensitized and non-sensitized rats. J. Hypertens. 6, 437-442.

Gomez-Sanchez, E.P., 1986. Intracerebroventricular infusion of aldosterone induces hypertension in rats. Endocrinology 118, 819-823.

Gomez-Sanchez, E.P., Fort, C.M., Gomez-Sanchez, C.E., 1990. Intracerebroventricular infusion of RU28318 blocks aldosterone-salt hypertension. Am. J. Physiol. 258, E482-E484.

Guyenet, P.G., 2006. The sympathetic control of blood pressure. Nat. Rev. Neurosci. 7, 335-346.

Holmes, M.C., Abrahamsen, C.T., French, K.L., Paterson, J.M., Mullins, J.J., Seckl, J.R., 2006a. The mother or the fetus? 11beta-hydroxysteroid dehydrogenase type 2 null mice provide evidence for direct fetal programming of behavior by endogenous glucocorticoids. J. Neurosci. 26, 3840-3844.

Holmes, M.C., Sangra, M., French, K.L., Whittle, I.R., Paterson, J., Mullins, J.J., Seckl, J. R., 2006b. 11 beta-Hydroxysteroid dehydrogenase type 2 protects the neonatal cerebellum from deleterious effects of glucocorticoids. Neuroscience 137, 865873.

Jarvie, B.C., Palmiter, R.D., 2017. HSD2 neurons in the hindbrain drive sodium appetite. Nat. Neurosci. 20, 167-169.

Johnson, A., Thunhorst, R., 2007. The neuroendocrinology, neurochemistry and molecular biology of thirst and salt appetite. In: Lajtha, A., Laustein, J. (Eds.), Handbook of Neurochemistry and Molecular Neurobiology: Behavioral Neurochemistry, Neuroendocrinology and Molecular Neurobiology. Springer, New York, pp. 641-687.

Koneru, B., Bathina, C.S., Cherry, B.H., Mifflin, S.W., 2014. Mineralocorticoid receptor in the NTS stimulates saline intake during fourth ventricular infusions of aldosterone. Am. J. Physiol. Regul. Integr. Comp. Physiol. 306, R61-R66.

Lincevicius, G.S., Shimoura, C.G., Nishi, E.E., Perry, J.C., Casarini, D.E., Gomes, G.N., Bergamaschi, C.T., Campos, R.R., 2015. Aldosterone contributes to sympathoexcitation in renovascular hypertension. Am. J. Hypertens. 28, 1083-1090.

Liu, J., Yosten, G.L., Ji, H., Zhang, D., Zheng, W., Speth, R.C., Samson, W.K., Sandberg, K., 2014. Selective inhibition of angiotensin receptor signaling through Erk1/2 pathway by a novel peptide. Am. J. Physiol. Regul. Integr. Comp. Physiol. 306, R619-R626. 
Masuda, T., Hirabara, Y., Nakamura, Y., Chishaki, A., Tsuruhisa, M., Miyakawa, M. Honda, K., Saito, R., Sakamoto, H., Kawata, M., Takano, Y., 2010. Aldosteronesensitive nucleus tractus solitarius neurons regulate sensitivity of the baroreceptor reflex in high sodium-loaded rats. J. Pharmacol. Sci. 112, 482-486.

Melo, M.R., Menani, J.V., Colombari, E., Colombari, D.S., 2015. Hydrogen peroxide attenuates the dipsogenic, renal and pressor responses induced by cholinergic activation of the medial septal area. Neuroscience 284, 611-621. https://doi. org/10.1016/j.neuroscience.2014.10.024.

Nakamura, Y., Takeda, K., Nakata, T., Hayashi, J., Kawasaki, S., Lee, L.C., Sasaki, S., Nakagawa, M., Ijichi, H., 1988. Central attenuation of aortic baroreceptor reflex in prehypertensive DOCA-salt-loaded rats. Hypertension 12, 259-266.

Naray-Fejes-Toth, A., Fejes-Toth, G., 1996. Subcellular localization of the type 2 11beta-hydroxysteroid dehydrogenase. A green fluorescent protein study. J. Biol. Chem. 271, 15436-15442.

Naray-Fejes-Toth, A., Fejes-Toth, G., 2007. Novel mouse strain with Cre recombinase in 11beta-hydroxysteroid dehydrogenase-2-expressing cells. Am. J. Physiol. Renal Physiol. 292, F486-F494.

Noguchi, K.K., Walls, K.C., Wozniak, D.F., Olney, J.W., Roth, K.A., Farber, N.B., 2008. Acute neonatal glucocorticoid exposure produces selective and rapid cerebellar neural progenitor cell apoptotic death. Cell Death Differ. 15, 1582-1592.

Odermatt, A., Arnold, P., Stauffer, A., Frey, B.M., Frey, F.J., 1999. The N-terminal anchor sequences of 11 beta-hydroxysteroid dehydrogenases determine their orientation in the endoplasmic reticulum membrane. J. Biol. Chem. 274, 28762 28770.

Odermatt, A., Dick, B., Arnold, P., Zaehner, T., Plueschke, V., Deregibus, M.N., Repetto, H., Frey, B.M., Frey, F.J., Ferrari, P., 2001. A mutation in the cofactor-binding domain of 11beta-hydroxysteroid dehydrogenase type 2 associated with mineralocorticoid hypertension. J. Clin. Endocrinol. Metab. 86, 1247-1252.

Paxinos, G., Watson, C., 1997. The Rat Brain in Stereotax Coordinates Vol.. Academic Press, Inc., San Diego.

Peysner, K., Henry, C.A., Malvin, R.L., 1990. Central infusion of aldosterone increases blood pressure by mechanisms independent of $\mathrm{Na}$ retention. Clin. Exp. Hypertens. A 12, 399-414.

Qiao, H., Hu, B., Zhou, H., Yan, J., Jia, R., Lu, B., Sun, B., Luo, X., Fan, Y., Wang, N., 2016. Aldosterone induces rapid sodium intake by a nongenomic mechanism in the nucleus tractus solitarius. Sci. Rep. 6, 38631.

Rahmouni, K., Barthelmebs, M., Grima, M., Imbs, J.L., Wybren De, J., 1999. Brain mineralocorticoid receptor control of blood pressure and kidney function in normotensive rats. Hypertension 33, 1201-1206.

Rahmouni, K., Sibug, R.M., De Kloet, E.R., Barthelmebs, M., Grima, M., Imbs, J.L., De Jong, W., 2002. Effects of brain mineralocorticoid receptor blockade on blood pressure and renal functions in DOCA-salt hypertension. Eur. J. Pharmacol. 436, 207-216.
Resch, J.M., Fenselau, H., Madara, J.C., Wu, C., Campbell, J.N., Lyubetskaya, A., Dawes, B.A., Tsai, L.T., Li, M.M., Livneh, Y., Ke, Q., Kang, P.M., Fejes-Toth, G., Naray-FejesToth, A., Geerling, J.C., Lowell, B.B., 2017. Aldosterone-sensing neurons in the NTS exhibit state-dependent pacemaker activity and drive sodium appetite via synergy with angiotensin II signaling. Neuron 96 (190-206), e7.

Robson, A.C., Leckie, C.M., Seckl, J.R., Holmes, M.C., 1998. 11 Beta-hydroxysteroid dehydrogenase type 2 in the postnatal and adult rat brain. Brain Res. Mol. Brain Res. 61, 1-10.

Roland, B.L., Krozowski, Z.S., Funder, J.W., 1995. Glucocorticoid receptor, mineralocorticoid receptors, 11 beta-hydroxysteroid dehydrogenase- 1 and -2 expression in rat brain and kidney: in situ studies. Mol. Cell Endocrinol. 111 R1-R7.

Sakai, R.R., Ma, L.Y., Zhang, D.M., McEwen, B.S., Fluharty, S.J., 1996. Intracerebral administration of mineralocorticoid receptor antisense oligonucleotides attenuate adrenal steroid-induced salt appetite in rats. Neuroendocrinology 64, 425-429.

van den Berg, D.T., de Kloet, E.R., van Dijken, H.H., de Jong, W., 1989. Brain corticosteroid receptors and regulation of arterial blood pressure. J. Hypertens Suppl. 7, S202-S203.

Van den Berg, D.T., de Kloet, E.R., de Jong, W., 1994. Central effects of mineralocorticoid antagonist RU-28318 on blood pressure of DOCA-salt hypertensive rats. Am. J. Physiol. 267, E927-E933.

Wang, W., 1994. Chronic administration of aldosterone depresses baroreceptor reflex function in the dog. Hypertension 24, 571-575.

Wang, W., McClain, J.M., Zucker, I.H., 1992. Aldosterone reduces baroreceptor discharge in the dog. Hypertension 19, 270-277.

Welling, P.A., 2013. Regulation of renal potassium secretion: molecular mechanisms. Semin. Nephrol. 33, 215-228.

Xue, B., Beltz, T.G., Yu, Y., Guo, F., Gomez-Sanchez, C.E., Hay, M., Johnson, A.K., 2011 Central interactions of aldosterone and angiotensin II in aldosterone- and angiotensin II-induced hypertension. Am. J. Physiol. Heart Circ. Physiol. 300, H555-H564.

Xue, B., Beltz, T.G., Johnson, R.F., Guo, F., Hay, M., Johnson, A.K., 2012. PVN adenovirus-siRNA injections silencing either NOX2 or NOX4 attenuate aldosterone/ $\mathrm{NaCl}$-induced hypertension in mice. Am. J. Physiol. Heart Circ Physiol. 302, H733-H741.

Yee, K.M., Struthers, A.D., 1998. Aldosterone blunts the baroreflex response in man. Clin. Sci. (Lond) 95, 687-692.

Zhang, Z.H., Kang, Y.M., Yu, Y., Wei, S.G., Schmidt, T.J., Johnson, A.K., Felder, R.B., 2006. 11beta-hydroxysteroid dehydrogenase type 2 activity in hypothalamic paraventricular nucleus modulates sympathetic excitation. Hypertension 48, $127-133$. 